\title{
Revising the Psychiatric Phenotype of Homocystinuria
}

\author{
Mohamed A. Almuqbil, MD, FRCPC ${ }^{1,2,3}$, Susan E. Waisbren, PhD ${ }^{1}$, Harvey L. Levy, MD ${ }^{1}$ and \\ Jonathan D. Picker, MBChB, PhD ${ }^{1,4}$
}

Purpose: Associations of psychiatric and psychological symptoms with homocystinuria (HCU) have been described in multiple reports. This retrospective study was undertaken to refine the psychological phenotype among HCU patients and identify biomedical markers that could be used for prediction of those psychiatric or psychological symptoms.

Methods: This study examines the prevalence of psychological symptoms within a sample of 25 patients with classical homocystinuria.

Results: Psychological symptoms were noted in 16 of the 25 patients in the sample (64\%), including a high prevalence of both anxiety (32\%) and depression (32\%) and correlated with IQ $<85$. There was no difference in the type or the number of psychological symptoms between those diagnosed from newborn screening and early treated and those treated after 2 years of age.
Conclusion: The results support the possible role of homocysteine as a risk factor for psychological and psychiatric problems and cognitive deficits and suggest that earlier diagnosis and treatment may reduce risk of their occurrences. Although early treatment clearly prevented serious medical complications, psychological and psychiatric symptoms were not associated with medical complications, highlighting the need for continued investigation.

Genetics in Medicine (2019) 21:1827-1831; https://doi.org/10.1038/s41436018-0419-4

Keywords: homocystinuria; psychological symptoms; psychiatric symptoms; depression; anxiety

\section{INTRODUCTION}

Homocystinuria (OMIM 236200) is a rare autosomal recessive metabolic disorder due to a defect in the cystathionine $ß$-synthase (CBS; EC 2.5.1.134) enzyme encoded by the CBS gene (OMIM 613381) (ref. ${ }^{1}$ ). Classical homocystinuria (HCU) occurs when CBS deficiency leads to homocysteine plasma levels that are typically $10-20$ fold higher than in the general population (normal reference range is $5-15 \mathrm{mmol} / \mathrm{L}$ ) (Fig. 1). Clinically, HCU results in a multisystem disorder with ocular, skeletal, cardiovascular, and central nervous system defects, though other organs can also be affected. ${ }^{2}$ Typical features, particularly in untreated patients, include early onset severe myopia, ectopia lentis, osteoporosis, a tall thin marfanoid habitus, scoliosis, thromboembolic events in early adulthood, and variably decreased IQ.

HCU was first reported in 1962 by Carson and Neil. ${ }^{3}$ Three years later, Schimke et al. described an association with psychiatric symptoms. ${ }^{4}$ Subsequent case reports highlighted an association between schizophrenia and other psychopathologies with HCU. ${ }^{5,6}$ However, it has been difficult to validate the psychiatric diagnoses in these early reports, as insufficient details were provided for comprehensive assessment. Furthermore, other reports linking schizophrenia with HCU did not appear to be supported on further review. ${ }^{7}$ Nevertheless, the association between HCU and psychopathology seemed to be supported by evidence that more than $50 \%$ of patients were affected by at least one psychological symptom including behavior disorders (17\%), depression (10\%), obsessive-compulsive disorder (7.6\%), and/or personality disorders (19\%) (ref. ${ }^{7}$ ). Since 1987 when this review appeared, additional case reports highlighting psychiatric disorders have become available.,

These reports support the hypothesis that elevations of methionine and homocysteine, the primary metabolites affected by homocystinuria, may indeed be involved with an expanded repertoire of psychiatric phenotypes. ${ }^{7}$ Of note, the incidence of depression in the general population is $7.6 \%$ per Centers for Disease Control and Prevention (CDC) reports. ${ }^{10}$

Methionine is the precursor of the methyl donor, s-adenosylmethionine (SAMe), which appears to regulate a wide range of genetic and biochemical processes with neuropsychiatric associations. ${ }^{11}$ In 1969 Beals reported that almost $50 \%$ of subjects develop psychopathology though it was

\footnotetext{
${ }^{1}$ Division of Genetics and Genomics, Boston Children's Hospital, Harvard Medical School, Boston, MA, USA; ${ }^{2}$ Division of Pediatric Neurology, King Saud bin Abdulaziz University for Health Sciences, Riyadh, Saudi Arabia; ${ }^{3}$ King Abdullah International Medical Research Center, King Abdullah Specialist Children's Hospital-Ministry of National Guard, Riyadh, Saudi Arabia; ${ }^{4}$ Department of Child \& Adolescent Psychiatry, Boston Children’s Hospital, Boston, MA, USA. Correspondence: Mohamed A. Almuqbil (malmuqbil@jhu.edu)
} 


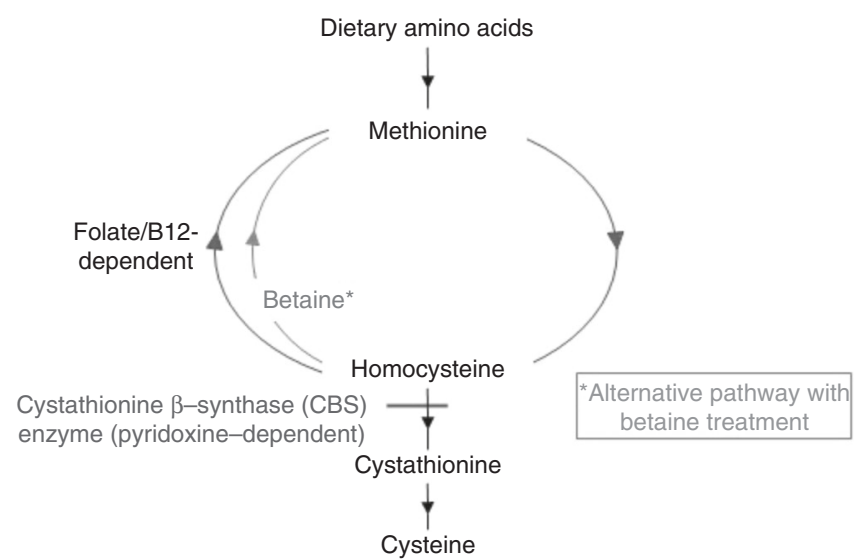

Fig. 1 Metabolic pathways involved in homocystinuria.

an initial presentation in only $2.8 \%$ of them. ${ }^{12}$ The presence of psychiatric symptoms in patients with increased methionine was associated with cognitive deficits, low scores on a memory scale, and an older age at diagnosis. ${ }^{8}$ Homocysteine itself is an effector at the N-methyl-D-aspartate (NMDA) receptor, which is implicated in cognitive deficits and schizophrenia. ${ }^{13}$ An opportunity thus exists to explore the relative roles of homocysteine and methionine in psychiatric phenotypes.

This retrospective study and literature review was undertaken to see if it was possible to refine the neuropsychological phenotypes observed among patients with HCU.

\section{MATERIALS AND METHODS}

This study included patients with HCU seen in a metabolism clinic in a tertiary hospital center. This project was approved by the Institutional Review Board, Boston Children's Hospital (BCH-IRB \#P00009045). Patients in the population were accessed through the scanning of the comprehensive computerized practice database of the hospital. Medical records of the identified patients were reviewed retrospectively extending to 1962 , to ensure that only patients with HCU were included.

Data were recorded using medical records review, patient report, and biochemical testing to include (1) medical history (age at diagnosis, treatment compliance, age at medical review, $B_{6}$ responsiveness) and comorbid medical complications; (2) biochemical data (average total plasma homocysteine [tHcy] level, highest methionine level); (3) treatment (diet, betaine, vitamin $\mathrm{B}_{6}$, folic acid, vitamin $\mathrm{B}_{12}$, and cysteine); (4) psychological symptoms listed in medical records; and (5) cognitive functioning (intelligence quotient [IQ], as assessed by age-appropriate standardized tests and subtests measuring cognitive abilities as well as memory and processing speed). To determine $\mathrm{B}_{6}$ responsiveness, individuals were routinely given at the time of diagnosis a pyridoxine challenge of up to $500 \mathrm{mg}$ orally for two days, followed by measurement of plasma homocysteine and amino acids at 48 hours after the oral challenge. In $\mathrm{B}_{6}$-responsive $\mathrm{HCU}$ there was a $30 \%$ or greater reduction in total homocysteine and methionine.
Table 1 Treatments reported

\begin{tabular}{lll} 
Treatment & Frequency & Percent \\
\hline Combined treatments $^{\mathrm{a}}$ & 24 & 92 \\
\hline Diet & 17 & 68 \\
Betaine & 17 & 68 \\
B $_{6}$ & 11 & 44 \\
\hline Folic acid/folate & 11 & 44 \\
B $_{12}$ & 9 & 36 \\
Cysteine & 7 & 28 \\
\hline
\end{tabular}

${ }^{\mathrm{a} C o m b i n e d ~ t r e a t m e n t s ~ i n c l u d e d ~ a n y ~ c o m b i n a t i o n ~ o f ~ t h e ~ l i s t e d ~ t r e a t m e n t s . ~ O n l y ~}$ one patient was treated with only betaine.

Correlational analyses were conducted using Pearson's correlation for continuous variables where relevant, and cross tabulations of categorical variables using Fisher's exact test to account for the limited sample size. Significance level was set at $p<0.10$ for the study, given the small sample size and the observational nature of the study.

Fisher's exact test was used to evaluate the relationship between presence of psychiatric symptoms (yes/no) and cognitive deficit (yes/no), as the data failed to meet assumption testing for chi square testing. For analyzing the relationship between age of diagnosis and presence of psychiatric symptoms, use of the chi square was acceptable, (although, Fisher's exact is provided as well). Cognitive deficit was defined as an IQ one standard deviation below the normative mean or more (IQ < 86). In addition, a Pearson's correlation coefficient was calculated to examine the relationship of presence of psychiatric symptoms with continuous variables collected for the study.

\section{Description of the sample}

The sample consisted of 25 patients, 13 males and 12 females, with a mean age of 33.5 years $(S D=14.96)$, median age of 29 (range $=4-55$ ). A total of $16(64 \%)$ of the patients in the sample reported systemic medical complications, with the most common being dislocated lens (ectopia lentis) $(n=11$, $44 \%)$ and osteoporosis $(n=7,28 \%)$. In terms of the subtype of disorder, $20(80 \%)$ were diagnosed $\mathrm{B}_{6}$-nonresponsive and 5 $(20 \%)$ as $B_{6}$-responsive. Newborn screening led to the identification of 14 cases. Clinical symptoms led to the diagnosis of 11 cases between the ages of 8 and 40 years. Treatments included diet, betaine, vitamin, $B_{6}$, folic acid, vitamin $B_{12}$, and cysteine, as noted in Table 1. Medical complications are listed in Table 2 along with age at diagnosis, with the assumption that early treatment was received with early diagnosis.

\section{RESULTS}

\section{Prevalence and type of psychiatric and psychological symptoms}

Clinically actionable psychological and psychiatric symptoms were noted in 16 of the 25 patients in the sample (64\%). Of those who were reported to have symptoms, 2 (12.5\%) were reported to require hospitalization for that symptom. The 
Table 2 HCU complications and age at diagnosis

$\begin{array}{lll}\text { Complication Frequency Percent } & \begin{array}{l}\text { Early } \\ \text { diagnosis }\end{array} & \text { Late } \\ & \text { diagnosis } \\ & \text { (i.e., by NBS) } & (8-40 \text { years) } \\ (N=14, & (N=11, \\ 56 \%) & 44 \%)\end{array}$

\begin{tabular}{lcccc}
\hline $\begin{array}{l}\text { Overall } \\
\text { systemic }\end{array}$ & 16 & 64 & 7 & 9 \\
$\begin{array}{l}\text { medical } \\
\text { complications }\end{array}$ & & & & \\
Dislocated & 11 & 44 & 3 & 8
\end{tabular}

lens

$\begin{array}{lllll}\text { Osteoporosis } & 7 & 28 & 4 & 3 \\ \text { Stroke } & 3 & 12 & 1 & 2\end{array}$

$\begin{array}{lllll}\text { Scoliosis } & 2 & 8 & 1 & 1\end{array}$

$\begin{array}{lllll}\text { DVT } & 2 & 8 & 1 & 1\end{array}$

$\begin{array}{lllll}\text { Myopia } & 1 & 4 & 0 & 1\end{array}$

$\begin{array}{lllll}\text { Ectopic lens } & 1 & 4 & 1 & 0\end{array}$

$\begin{array}{llll}\text { Hypertension } & 1 & 4 & 0\end{array}$

$\begin{array}{lllll}\text { Glaucoma } & 1 & 4 & 0 & 1\end{array}$

$\begin{array}{lllll}\text { PE } & 1 & 4 & 1 & 0 \\ \text { Joint } & 1 & 4 & 0 & 1\end{array}$

problems

$\begin{array}{lllll}\text { Osteopenia } & 1 & 4 & 0 & 1\end{array}$

DVT deep venous thrombosis, HCU homocystinuria, NBS newborn screening, $P E$ pulmonary embolism.

symptoms reported included anxiety and depression (32\% each), as well as issues with anger and aggression, mood swings, suicidal thoughts, and other symptoms as noted in Table 3. Eight of the 16 patients with psychiatric and psychological symptoms reported more than one symptom. There was no difference in either the number or types of psychological symptoms between those diagnosed from newborn screening and early treated and those diagnosed and treated after 2 years of age.

Of the 16 study participants who were reported to have psychiatric symptoms, most presented as comorbidities. Of those who experienced depression $(n=8)$, three participants reported depression as the only psychological symptom and five reported both anxiety and depression, with or without other psychiatric and psychological issues such as attention deficit-hyperactivity disorder (ADHD), oppositional defiant disorder (ODD), mood swings, hallucinations, and suicidal thoughts. Among those who were noted to have anxiety as a symptom $(n=8)$, two had anxiety as the only symptom whereas five experienced both anxiety and depression. In three participants, ADHD was reported as comorbidity.

In total, 9 of the 25 participants $(36 \%)$ in the sample received treatment at some point of time with medication for psychological and psychiatric symptoms. Medications included Zoloft $(n=3,12 \%)$, Risperdal $(n=2,8 \%)$, and Zyprexa $(n=2,8 \%)$, as well as Ritalin, Ativan, methylphenidate, Seroquel, and Welbutrin ( $n=1$, or $4 \%$ for each). From the medical records it was unclear whether the medications
Table 3 Psychiatric symptoms in different groups

\begin{tabular}{|c|c|c|c|c|}
\hline Symptom & $\begin{array}{l}\text { Number } \\
\text { affected }\end{array}$ & Percent & $\begin{array}{l}\text { Early } \\
\text { diagnosis } \\
\text { (i.e., by NBS) } \\
(N=14,56 \%)\end{array}$ & $\begin{array}{l}\text { Late } \\
\text { diagnosis } \\
(8-40 \text { years) } \\
(N=11, \\
44 \%)\end{array}$ \\
\hline
\end{tabular}

\begin{tabular}{|c|c|c|c|c|}
\hline Anxiety & 8 & 33 & 4 & 4 \\
\hline Depression & 8 & 33 & 3 & 5 \\
\hline ADHD/ADD & 3 & 12 & 2 & 1 \\
\hline $\begin{array}{l}\text { Anger/ } \\
\text { aggression }\end{array}$ & 2 & 8 & 1 & 1 \\
\hline Suicidal & 2 & 8 & 2 & 0 \\
\hline Drug abuse & 2 & 8 & 1 & 1 \\
\hline $\begin{array}{l}\text { Social } \\
\text { isolation }\end{array}$ & 2 & 8 & 0 & 1 \\
\hline $\begin{array}{l}\text { Behavioral } \\
\text { symptoms }\end{array}$ & 1 & 4 & 0 & 1 \\
\hline Hallucinations & 1 & 4 & 1 & 0 \\
\hline Mood swings & 1 & 4 & 1 & 0 \\
\hline ODD & 1 & 4 & 0 & 1 \\
\hline Paranoia & 1 & 4 & 0 & 1 \\
\hline PDD & 1 & 4 & 1 & 0 \\
\hline
\end{tabular}

$A D D$ attention deficit disorder, $A D H D$ attention deficit-hyperactivity disorder, $N B S$ newborn screening, $O D D$ oppositional defiant disorder, $P D D$ pervasive developmental disorder.

for treatment were associated with any adverse effects in the sample or to what extent these medications were effective.

\section{Cognitive deficits}

We performed neurocognitive testing on 15 of the 25 patients. The mean Full Scale (FS) IQ was $84 \pm 18$, in the borderline range, more than a standard deviation below the population norm $(100 \pm 15)$. Mean verbal IQ $(89 \pm 18)$ was slightly higher, in the low average range, as was the mean score on the memory subtest $(86 \pm 17)$. The mean processing speed score was $84 \pm 18$.

In $60 \%$ of cases the FS IQ was one standard deviation or more below the FS IQ normative population mean; 26\% of these cases performed in the range of intellectual disability at $>2$ standard deviations below the normative mean (FS IQ $<70$ ).

\section{Associations between presence of psychiatric symptoms and other variables}

Results indicated that the presence of psychiatric symptoms correlated with having a cognitive deficit (IQ < 85) (Fisher's exact $p=0.011)$. The presence of psychiatric symptoms was associated with older age at time of diagnosis $(r=9.07, p=$ $0.065)$ and lower scores on measures of memory $(r=-0.650$, $p=0.058)$. Among the patients recorded as having cognitive deficits, all but $1(10 / 11,91 \%)$ were reported to have psychiatric symptoms whereas 5 (38\%) patients with IQ within or above 1 standard deviation of the normative mean (IQ $>85 ; n=13$ ) were reported to have psychiatric symptoms. Patients diagnosed by newborn screening (NBS) 
Table 4 Correlations with presence of psychiatric symptoms and other variables

\begin{tabular}{|c|c|c|c|c|}
\hline Variable 1 & Variable 2 & $\begin{array}{l}\text { Statistical } \\
\text { test }\end{array}$ & $p$ value & Conclusion \\
\hline \multirow{8}{*}{$\begin{array}{l}\text { Presence of } \\
\text { psychiatric } \\
\text { symptoms }\end{array}$} & $\begin{array}{l}\text { Non-normal } \\
\text { cognition }^{a}\end{array}$ & Fisher's exact & 0.011 & $\begin{array}{l}\text { Significant } \\
\text { correlation }\end{array}$ \\
\hline & $\begin{array}{l}\text { Memory } \\
\text { score }^{b}\end{array}$ & Pearson's $r$ & 0.058 & $\begin{array}{l}\text { Nearly } \\
\text { significant }\end{array}$ \\
\hline & Sex & $\begin{array}{l}\text { Chi square/ } \\
\text { Fisher's exact }\end{array}$ & $\begin{array}{l}0.072 / \\
0.111\end{array}$ & $\begin{array}{l}\text { Nearly/not } \\
\text { significant }\end{array}$ \\
\hline & Age & Pearson's r & 0.342 & $\begin{array}{l}\text { Not } \\
\text { significant }\end{array}$ \\
\hline & Compliance & $\begin{array}{l}\text { Chi square/ } \\
\text { Fisher's exact }\end{array}$ & 0.967 & $\begin{array}{l}\text { Not } \\
\text { significant }\end{array}$ \\
\hline & $\begin{array}{l}\text { Type of } \\
\text { disorder }\end{array}$ & $\begin{array}{l}\text { Chi square/ } \\
\text { Fisher's exact }\end{array}$ & 0.328 & $\begin{array}{l}\text { Not } \\
\text { significant }\end{array}$ \\
\hline & Total Hcy & $\begin{array}{l}\text { Chi square/ } \\
\text { Fisher's exact }\end{array}$ & 0.733 & $\begin{array}{l}\text { Not } \\
\text { significant }\end{array}$ \\
\hline & $\begin{array}{l}\text { Highest } \\
\text { meth }\end{array}$ & Pearson's r & 0.843 & $\begin{array}{l}\text { Not } \\
\text { significant }\end{array}$ \\
\hline \multirow{2}{*}{$\begin{array}{l}\text { Presence of } \\
\text { medical } \\
\text { complications }\end{array}$} & Total Hcy ${ }^{\mathrm{a}}$ & Fisher's exact & 0.047 & Significant \\
\hline & $\begin{array}{l}\text { Highest } \\
\text { meth }^{a}\end{array}$ & Pearson's r & 0.041 & Significant \\
\hline
\end{tabular}

Hcy homocysteine, meth methionine.

asignificant correlation at $p<0.05$.

${ }^{b}$ Significant correlation at $p<0.10$.

$(n=14)$ were less likely to have psychiatric symptoms $\left(X^{2}=\right.$ 3.90, $p=0.048$; Fisher's exact, 1 -tailed $p=0.058$ ).

No correlations were found between the presence of psychological symptoms and the variables of treatment compliance $(p=0.967)$, age $(p=0.342)$, type of disorder (categorized as $\mathrm{B}_{6^{-}}$vs. $\mathrm{B}_{6}+; p=0.328$ ), total Hcy level (categorized as $<100$ vs. $>100 ; p=0.733$ ), and highest methionine level ( $p=0.843$ ) (Table 4).

\section{DISCUSSION}

Homocystinuria is an autosomal recessive disorder that is caused by deficiency of an enzyme called cystathionine $\beta$ synthase (CBS). This study documented increased prevalence of psychological and psychiatric findings in patients with classical homocystinuria due to CBS deficiency (HCU) despite their receiving conventional treatments. Primary treatments included protein restricted diet, betaine, vitamin $\mathrm{B}_{6}$, folic acid, vitamin $\mathrm{B}_{12}$, and cysteine. Psychological symptoms were noted in 16 of the 25 patients in the sample (64\%), almost twice the prevalence reported in general populations ${ }^{14}$ and higher than estimates of $30-50 \%$ for individuals with comorbid intellectual disabilities. ${ }^{15}$ Psychiatric disorders reported include a high prevalence of anxiety (32\%) and depression (32\%), and less frequently, anger and aggression, mood swings, suicidal thoughts, and other psychotic symptoms like hallucinations.
There was a lower frequency of $\mathrm{B}_{6}$-responsive patients with psychiatric symptoms, $20 \%$ in our study, than the estimated $50 \%$ of all those with HCU, perhaps consistent with the generally milder disease in $\mathrm{B}_{6}$-responsive patients ${ }^{2}$ and similar to the findings of others. ${ }^{7}$

Similar to previous studies, our study documented the presence of psychiatric and psychological symptoms in people with HCU. These symptoms included anxiety, depression, anger, aggression, suicidal thoughts, and hallucinations. The presence of psychiatric symptoms was associated with cognitive deficits, low scores on a memory scale, and an older age at diagnosis. All but one of the patients with cognitive deficits experienced psychiatric symptoms. However, the presence of psychiatric symptoms was not a simple manifestation of low IQ, as those with higher IQ also experienced symptoms at a higher rate than the general population. Compared with data from the CDC, ${ }^{10}$ depression occurs in $7.6 \%$ in the general population of individuals age 12 years and older. These results support the possible role of homocysteine as an effector implicated in psychological and psychiatric symptoms leading to cognitive deficits. ${ }^{16,17}$ However, our results could not determine if psychiatric symptoms emerge as the individual with HCU ages or if they are a longterm complication of late treatment, because most of the older individuals in this study were not identified by newborn screening.

Early reports described schizophrenia as a complication of homocystinuria. ${ }^{4,6}$ However, later review of the data did not support this conclusion, ${ }^{7}$ consistent with our current work. Instead, patients in this study experienced significant but less severe psychopathology. These less severe symptoms included cognitive problems, personality disorders, behavioral disorders, anxiety, and depression. ${ }^{7}$ The early findings of schizophrenia could be a function of lack of diet and betaine. Diet for treatment of this disease was not developed until the mid to late 1970s and the importance of betaine was discovered even later. ${ }^{18}$ This may be a factor in the more prominent psychiatric problems reported in the early reports, as those patients were essentially untreated. Moreover, some studies found other psychiatric symptoms more prevalent than schizophrenia, which was present in only a few cases of HCU. $^{11}$

Many theories have been associated with psychiatric and psychological manifestations of HCU. These include its association with NMDA receptors, which are central to the glutamatergic role in psychiatric illness. An oxidation product of homocysteine acts as an antagonist on NMDA receptors. This can lead to psychological and psychiatric symptoms. Further, glutaminergic dysfunction caused by raised homocysteine levels was also reported as a cause of delusional misidentification syndrome (DMS). ${ }^{19}$ Alternation in DNA methylation can have an important role with SAMe and SAHcy as activator and inhibitor of COMT respectively. Elevated homocysteine and SAH in serum and tissues are associated with schizophrenia as $\mathrm{SAH}$ is an inhibitor of COMT and causes aberrant methylation. ${ }^{20}$ 
The data trends suggest that earlier diagnosis (and assumed early treatment) reduces risk for psychiatric symptoms. On the other hand, the presence of psychiatric symptoms was not associated with medical complications, an association that would seem likely if early treatment and diagnosis were indeed preventing complications from homocystinuria. This study was limited by the small sample and the inclusion of older patients for whom treatment options when they were diagnosed may not have been as effective as present treatment options. In addition, it is possible that having a chronic condition contributes to feelings that lead to depression and/ or anxiety. Given the possible connection between early diagnosis and treatment, further research would be valuable in evaluating treatment options. In particular, the use of psychotropic medications and their associated effectiveness in reducing psychological symptoms should be studied. Another limitation was the sole use of retrospective medical records. A prospective, natural history study would permit more robust analyses of the effect of early diagnosis, varying treatments, and progression of the condition over time. Despite these limitations, this study provides evidence for the association between the biochemical perturbations in CBS homocystinuria and psychiatric symptoms.

\section{DISCLOSURE}

The authors declare no conflicts of interest.

Publisher's note: Springer Nature remains neutral with regard to jurisdictional claims in published maps and institutional affiliations.

\section{REFERENCES}

1. OMIM. Cystathionine beta-synthase (CBS). Baltimore, MD: Johns Hopkins University, Center for Medical Genetics; 2010. http://omim.org/entry/ 613381.

2. Mudd SH, Skovby F, Levy HL, et al. The natural history of homocystinuria due to cystathionine $\beta$-synthase deficiency. Am J Hum Genet. 1985;37:1-31.
3. Carson NAJ, Neill DW. Metabolic abnormalities detected in a survey of mentally backward individuals in Northern Ireland. Arch Dis Child. 1962;37:505-513.

4. Schimke RN, McKusick VA, Huang T, Pollack AD. Homocystinuria. Studies of 20 families with 38 affected members. JAMA. 1965;193:711-719.

5. Kaesar AC, Rodnight R, Ellis BA. Psychiatric and biochemical aspects of a case of homocystinuria. J Neurol Neurosurg Psychiatry. 1969;32:88-93.

6. Rahman M. Homocystinuria review of four cases. $\mathrm{Br} J$ Ophthalmol. 1971;55:338-342.

7. Abbott $\mathrm{MH}$, Folstein SE, Abbey $\mathrm{H}$, et al. Psychiatric manifestations of homocystinuria due to cystathionine beta-synthase deficiency: prevalence, natural history, and relationship to neurologic impairment and vitamin B6-responsiveness. Am J Med Genet. 1987;26:959-969.

8. Mazzei DH, Rodriguez SM, Moltó PH, et al. A forgotten lethal psychosis: a case report. Eur Child Adolesc Psychiatry. 2014;23:235-238.

9. Colafrancesco G, Di Marzio GM, Abbracciavento G, et al. Acute psychosis in an adolescent with undiagnosed homocystinuria. Eur J Pediatr. 2015;174:1263-1266.

10. Centers for Disease Control and Prevention (CDC). 2013. Available at https://www.cdc.gov/nchs/fastats/depression.htm.

11. Bracken P, Coll P. Homocystinuria and schizophrenia. Literature review and case report. J Nerv Ment Dis. 1985;173:51-55.

12. Beals RK. Homocystinuria: a report of two cases and review of the literature. J Bone Joint Surg Am. 1969;51:1564-1572.

13. Ohgi Y, Futamura T, Hashimoto K. Glutamate signaling in synaptogenesis and NMDA receptors as potential therapeutic targets for psychiatric disorders. Curr Mol Med. 2015;15:206-221.

14. Kessler RC, et al. The global burden of mental disorders: an update from the WHO World Mental Health (WMH) Surveys. Epidemiol Psichiatr Soc. 2009;18:23-33.

15. Munir KM. The co-occurrence of mental disorders in children and adolescents with intellectual disability/intellectual developmental disorder. Curr Opin Psychiatry. 2016;29:95-102.

16. Coyle JT, Tsai G, Goff D. Converging evidence of NMDA receptor hypofunction in the pathophysiology of schizophrenia. Ann N Y Acad Sci. 2003;1003:318-327.

17. Lipton SA, et al. Neurotoxicity associated with dual actions of homocysteine at the N-methyl-D-aspartate receptor. Proc Natl Acad Sci USA. 1997;94:5923-5928.

18. Wilcken DE, Wilcken B, Dudman NP, Tyrrell PA. Homocystinuria-the effects of betaine in the treatment of patients not responsive to pyridoxine. N Engl J Med. 1983;309:448-453.

19. Rahman T, Cole EM. Capgras syndrome in homocystinuria. Biol Psychiatry. 2014;76:e11-2.

20. Singh SM, Murphy B, O'Reilly RL. Involvement of gene-diet/drug interaction in DNA methylation and its contribution to complex diseases: from cancer to schizophrenia. Clin Genet. 2003;64:451-460. 